\title{
Análisis de una propuesta didáctica para trabajar la poesía en un aula de Primaria: leer a Leopoldo de Luis'
}

\author{
SERGIO ARLANDIS \\ Universidad de Valencia \\ JOSEP M. RODRÍGUEZ \\ Universidad de Lleida \\ España \\ sergio.Arlandis@uv.es \\ josepmrodriguez@hotmail.com
}

Analysis of a Didactic Initiative to Work With Poetry Texts in an

Elementary Classroom: Reading Leopoldo de Luis

(Recibido: 2O-I2-2O2O; aceptado: $\mathrm{I}_{4}-\mathrm{O} 4-2 \mathrm{O} 2 \mathrm{I}$ )

Resumen. Muchas son las propuestas para llevar la lectura de un poema a un aula, aunque los resultados, a pesar de las buenas voluntades, no siempre son muy satisfactorios, quizá porque sea parte de una idea algo equivocada de lo que es un texto poético y de lo que este requiere. En este trabajo se pretende revisar todo ello, valorando, además, la idoneidad de un poema del poeta Leopoldo de Luis, sobre un partido de fútbol. Frente a esta propuesta se ha llevado a cabo toda una revisión seria de los resultados obtenidos en su aplicación, tanto en un aula de Primaria como en unos grupos de estudiantes universitarios. Los resultados son esclarecedores y también inquietantes en algunos sentidos, pues evidencian demasiadas carencias, tanto en su hábito lector como en la manera de trabajar la poesía en las aulas.

Palabras clave: canon; poesía ganada; intertextualidad; hábito lector; proceso de lectura.
Abstract. There are many proposals that bring poetry reading into the classroom, although the results, even with good will, are not always very satisfactory, perhaps because they begin with the wrong idea of what a poetic text is and what this requires. In this study we intend to review these ideas, assessing the suitability of a poem by Leopoldo de Luis, about a football game. We have made a serious review of the results obtained in its implementation, both in an Elementary classroom and in some groups of university students. The results are both enlightening and disturbing in some ways, as they show too many deficiencies, both in reading habits and in the ways of working with poetry in the classroom.

Keywords: canon; earned poetry; intertextuality; reading habit; reading process.

\footnotetext{
I Para citar este artículo: Arlandis, Sergio y Rodríguez, Josep M. (2O2I). Análisis de una propuesta didáctica para trabajar la poesía en un aula de Primaria: leer a Leopoldo de Luis. Alabe 24 . [www.revistaalabe.com]

DOI: IO.I5645/Alabe2O2I.24.9
} 


\section{r. Lectura de un texto literario en un aula de Primaria: predisponer, disponer, me-} diar.

El aula, dentro del amplio marco o espectro de los niveles educativos que van del ciclo de infantil hasta el superior universitario, es siempre (o debería serlo) un espacio de dinamización de las diferentes competencias sociales, culturales, comunicativas y cognitivas que nos definen, tanto a docentes como a estudiantes. Para que esto pueda suceder es necesaria la implicación activa y dinámica del/la estudiante y del profesor/a (y lo decimos con este orden de manera deliberada). A este factor fundamental de la enseñanzaaprendizaje de base constructivista lo hemos vinculado con la motivación. Y para que dicha motivación exista son muchas las guías que se han trazado al respecto y que tampoco vemos necesario recuperar para el festín bibliográfico: por ejemplo, señala Isabel Solé, en su libro Estrategias de lectura (2002), que la mejor manera de motivar a los más jóvenes en la lectura (sea de un texto literario o no) es que el o la docente ofrezca al/la estudiante retos asequibles, que pueda alcanzar y afrontar, aunque persista el riesgo de no cumplir con los objetivos marcados a priori. Y para que esto pueda llevarse a cabo lo más indicado (dice Solé) es que los/las propios estudiantes ya tengan una base de conocimientos previos, de tal manera que el texto les resulte, de algún modo familiar.

El poema sugerido, esta vez, para trabajar en un aula de Primaria escapa de ese canon, más o menos establecido, que viene señalándose para la poesía infantil, sea su naturaleza la que sea (Cervera, I997: I2I-I92; López Tamés, I99O: I5I-2I7; Cerrillo, I996: II6-II7; Perriconi y Wischñevsky, I984: 3-II; Colomer, I999: I55-I58): personificación de animales, juego de la palabras, ambiente lúdico o la recreación en los efectos fónicos; sin embargo, sí atiende a otros, visibles igualmente, tales como la intertextualidad, que aproxima al lector a unos textos abiertos a su alrededor, cierta predominancia al contar frente al cantar, es decir, prevalece una voluntad narrativa detrás de su forjado ritmo versal; unido al sensorialismo agudizado y un leve esbozo - como señalara Juan Cervera (r997: I35) muy tempranamente a la hora de fijar las características más representativas de la poesía infantil contemporánea- de compromiso social, más allá de la aparición central de los niños como protagonistas. No obstante, señalar la existencia de unas características o rasgos más o menos regulares y recurrentes no obliga ni a cumplirlos en su totalidad ni a tener que constreñirse a ellos, por muy canónicos que pudieran resultar. Tampoco sugerimos, en todo caso, que la poesía de Leopoldo de Luis sea modélica, en su conjunto, para tratarse en un aula de Primaria, aunque sí arroja bastantes resultados positivos una vez se tratan muchos de sus textos, tanto en Primaria como en Secundaria. Por tanto, en este sentido, coincidimos plenamente con las apreciaciones de Pedro Cerrillo y Ángel Luis Luján (20IO: I8) cuando apuntaban a que la selección de textos poéticos para el aula debe ayudar, sobre todo, a que el alumnado opere «con un concepto de adscripción categorial que sea flexible y responda más fielmente al funcionamiento del pensamiento real», porque, en verdad, como también sugirió Jaqueline Held (I977: I6I) el «niño siempre necesita textos adultos, un baño de lenguaje adulto» aunque a veces ese mismo lenguaje adulto pueda entenderse como un «obstáculo»: frente a la ternura de los prime- 
ros poemas o su despreocupación, no hay que negar la concienciación, la reflexión y el compromiso frente a lo que les rodea.

Tengamos igualmente presente que un autor/ra diseña, bajo convenciones, unas estrategias que pasan por la selección de un tipo de género y sus concreciones formales exigidas, más allá de posibles experimentaciones que pueden darse, un tipo de lenguaje, un tipo de formato exterior en connivencia con el editor, una temática con un desarrollo acorde a su recepción, etc., aunque, en su gran mayoría se impone la mirada del adulto/a, adaptada a la visión del niño o niña. Lo cierto es que, en la confección de la obra, en la selección de sus formantes temáticos y estructurales, se impone la sombra de su receptor. Esta toma de decisión acaba por confeccionar unos hipotéticos referentes de la escritura que llamaremos lector modelo, según se ha venido estudiando, con mayor o menor acierto, en muchos casos. Y en el caso del poema delusiano no parece que el lector infantil fuera su destinatario modélico, aunque tampoco se le excluye o se le restringe especialmente.

El propio lector (ya en bajos niveles de formación lectora) es consciente de que todo texto tiene uso y se aventura a la lectura con la voluntad de medirse como tal: si un libro está marcado- por la editorial- para la edad de entre 7 y 9 años y a él quiere acceder un niño o niña de 6 años, es muy probable que, a pesar del esfuerzo, el/la joven lector piense que no ha entendido buena parte de lo leído, aunque ese esfuerzo habrá proporcionado más éxito del que espera o esperaba, pues habrá supuesto- no de manera casuística y plenamente garantizada - un esfuerzo ante la complejidad exigida y habrá avanzado (solo si antes no se ha desmoralizado) en su comprensión lectora. Así, queda evidente que, muchas veces, la literatura ganada implica (aunque no siempre) un esfuerzo lector que suele recompensar a quien lo efectúa. Dicho progreso, pues, acabará certificándose cuando el propio niño o niña, tiempo después, tenga la necesidad, voluntad o curiosidad de retomar su lectura para volverse a medir (Melanio y Dávila, 2OI8; Sevilla, 2OI8). Pero es cierto que también puede ocurrir lo contrario, como sucede con la poesía, por desgracia y habría que preguntarse por qué.

Frente a esto, cuando un lector siente que su capacidad está muy por encima de lo que el texto puede ofrecerle, pierde parte de su interés, ya que siente/piensa que no puede establecerse un horizonte de expectativas más complejo, que dote de una significación mayor a lo leído, así que solo queda aferrarse al disfrute de lo leído (quizá porque la temática en sí le atraiga sobremanera) o a la búsqueda de nuevos horizontes insospechados de lo releído, tal vez, también, por sentir la satisfacción de sentirse plenamente dominadores de su lectura, de las inferencias iniciales total o parcialmente confirmadas a su entender. El caso está que, cada vez que nos ponemos ante un texto (o pretendemos hacerlo), usamos ese canon (medida) personal que nos sitúa en una escala predeterminada por nuestra propia experiencia lectora y nos augure- creemos- una serie de resultados que serán confirmados o desechados cuando comencemos a leer. Y aquí es fundamental que el lector sienta total seguridad frente al texto, ya que cualquier titubeo corre el riesgo de encaminarlo al abandono y a la desmotivación. 
Pero este lector que avanza en el desarrollo de sus competencias no solo se nutre de lecturas realizadas o conocidas, que le permiten poner en relación aquellos textos evocados con este texto presente. Necesita ser conocedor de esos convencionalismos formales y temáticos propios de los textos literarios, que le permitan también acceder a cómo el autor/ra ha diseñado su propia estrategia. En este sentido, cuanto mayor sea la cosificación de esas estrategias y se ajuste a los modelos más canónicos, más fácil será identificar el andamiaje del texto; por el contrario, cuanto menor sea la experimentación y más laxa sea la aplicación de esos convencionalismos, más difícil será acceder a ellos o, incluso, más fácil será su valoración estética, para bien o para mal. En consecuencia, si gran parte del objetivo de la literatura infantil y juvenil es acompañar a estos/as jóvenes lectores hacia la lectura adulta ¿por qué no usar textos también que garanticen ese tránsito en su formación?

Frente a lo señalado, el primer paso para esa motivación lo debe dar el docente (al que el método constructivista llamará mediador), al cotejar los conocimientos previos de los niños y las niñas, y en buscar un texto que pueda ajustarse a ellos, con el fin de alimentar una confianza clave en todo proceso de adquisición y desarrollo de la competencia lectora. Así, no solo se garantizaría la comprensión del texto, sino también se multiplicarían las posibilidades de interpretación de los mismos en su fase final o como culminación de un proceso de lectura progresivo, gradual y continuo.

Una vez puestos ya en el trabajo en el aula para incardinar ese antes/durante/ después de la lectura como eje de las actividades sobre el texto, debemos valorar que estemos dentro de unos indicios razonables de eficacia de todo el proceso lector, encaminado (hay que recordarlo) hacia una mayor autonomía del propio lector y esto implica una mayor competencia lectora y literaria y, en suma, comunicativa, aunque dicha autonomía se fundamente en el paso de la oralización a la lectura silenciosa progresivamente, del mismo modo que oscila del juego al desarrollo intelectual (adquisición de conocimientos específicos). Es decir, es necesario vigilar, guiar y orientar al/la estudiante para que la búsqueda de significado (intertextual en cuanto a comprensión y extratextual en cuanto a interpretación) no se convierta en extravío y, por tanto, en fracaso. La pregunta es la siguiente: ¿en qué medida el trabajo de la poesía en el aula no acaba en estas lides? Es decir, ¿por qué la lectura de poesía no resulta nada motivadora una vez se ha pasado la etapa del juego fónico y metafórico tan característica del período infantil y del primer ciclo de primaria (hasta los 9 años)? De hecho, un segundo eje de motivación es la confección de unos objetivos delimitados de por qué debemos leer y qué buscamos con ello.

Recordemos, con Daniel Cassany, Marta Luna y Gloria Sanz (2000) que existen cuatro tipos de lectura silenciosa:

- Por un lado, la lectura extensiva, que es aquella que realizamos por placer o por interés.

- Por otro, una lectura intensiva, que es aquella cuyo objetivo es el de obtener información de un texto. 
- También está la lectura rápida y superficial que es aquella que busca obtener información de un texto, pero de un modo más rápido y selectivo, y que curiosamente está siendo este el modelo de lectura más en auge debido a cómo nos estamos acostumbrando a la lectura a través de redes sociales, principalmente (Arlandis, 20I8: 8I-IOO).

- Y por último, la lectura involuntaria, que es aquella que, de manera instintiva y automática, realizamos en nuestra vida cotidiana.

Cada situación de lectura necesita, por tanto, una actitud y una formación del lector, y para leer un texto literario (poético o no) hay que superar la fase de la simple lectura rápida y superficial, tanto como la involuntaria o la intensiva, mucho más pragmática pero un tanto al margen de lo que podríamos denominar hábito lector. Así, no podemos pasar por alto que el objetivo principal, dentro de un listado más o menos reducido de los objetivos específicos de cada actividad, curso y ciclo, es formar a los alumnos y alumnas a realizar lecturas intensivas eficientes con el objetivo (insistamos en el término) de que sus propias lecturas extensivas sean lo más completas y productivas posibles (ajustadas a edad) para el desarrollo intelectual y social del/la estudiante, porque como defiende el propio Daniel Cassany en su libro Taller de textos (2006), leer y comprender son también tareas sociales.

Visto así, toda lectura (literaria o no) debe socializar porque de eso se trata, según los parámetros constructivistas (Coll et alii, ı993; Díez de Ulzurrun, 2003; Kozak, Kriscautzky y Díaz, I994). Ahora bien, cabe volverse a hacer las preguntas que ya nos formulamos anteriormente y añadir otras como: ¿por qué un amplio y vasto sector de los/las jóvenes estudiantes de Primaria, Secundaria, Bachillerato y Universidad no ven la poesía como un elemento de socialización, sino todo lo contrario, como una práctica de aislamiento, marginalización e incomunicación? Quizá las estrategias de intervención docente, en este caso, siempre esperan salvar este riesgo colateral.

Tal vez nos hemos cansando de decir excesivas veces que debe imponerse el placer de leer, la lectura despreocupada de cualquier fin, no porque opinar esto sea negativo sino por cómo ha ido derivando dicho concepto: se ha trivializado tanto el hecho de leer dentro de una sociedad capitalista que ha querido hacer de la lectura un efecto más del vacuo y consumista ocio. En consecuencia, cuesta convencer (o motivar) de que la lectura aporta un conocimiento, una visión de la realidad o una perspectiva crítica de los hechos, necesaria para el presente. Todo se ha reducido, entonces, al placer de leer (y es que una cosa es considerarlo el principal foco y otra que se produzca como consecuencia) y esto implica que la escritura cada vez se aleja más (aunque no sea así) del compromiso social que siempre ha atendido, en una deformación del concepto del placer de la lectura (Moreno, 2OII). Sin duda, quienes están forjando un nuevo modelo social y cultural (en torno a ese pensamiento débil postmoderno anunciado por Lyotard, Vattimo o Habermas entre otros) han cuidado con sumo detalle esa descentralización del mercado editorial y del gusto lector hacia modelos más efímeros, casi de usar y tirar, e impregnados de la 
necesidad de vender ejemplares, porque de eso, y no de formar lectores competentes, parece tratarse. Han sabido anticiparse en la confección de un público lector y les han convencido con un tipo de discurso, cuanto menos, engañoso. Por ejemplo, cuando un o una estudiante lee un poema erótico firmado por Defreds o Diego Ojeda, o por Irene $\mathrm{X}$ o de cualquier influencer de estos que ahora salen como ranas de una charca ¿es más cercano a su mundo? ¿tiene mejores conocimientos previos o simplemente ha actuado sobre ellos el márquetin? Si el poema erótico-amoroso lo escribiese Pedro Salinas, con un lenguaje más cuidado y con una forma más precisa y rítmica ¿no tendrían los mismos conocimientos previos? ¿no sería el mismo lenguaje o es que acaso si un joven lee aquello de «perdóname por ir así buscándote, / tan torpemente, dentro / de ti. / Perdóname el dolor, alguna vez» del propio Salinas, un/una estudiante no lo comprendería mejor que el verso de Luna Miguel, que merece todo respeto a su labor poética, en el que dice «el corazón que hubo en mi vientre fue corazón y no latía»? Creemos que el argumento del lenguaje empleado ya tampoco es tan válido y la proximidad de mundo o de inquietudes, tampoco. No se trata de hacer crítica alguna a nadie, sino de tratar de entender por qué se trabajan y se leen ciertos poetas y otros, en cambio, no. Y decimos más: se trata de afirmar por qué es necesario leer a otros poetas (como es el caso de Leopoldo de Luis y muchos otros) en ciertas edades, pues su lectura, que es bien actual, ayuda a cimentar una base ética, solidaria y crítica, necesaria para la formación integral de los/las más jóvenes, pues- volvemos a insistir-de lo que se trata es de sociabilizar.

\section{La riqueza expresiva de Leopoldo de Luis como garantía de la calidad del texto: algunas claves de su poesía.}

La poesía de Leopoldo de Luis ha tenido importantes reconocimientos y premios, pero no ha bastado hasta la fecha: desde el Nacional de Poesía con Igual que guantes grises (1979), el Premio Nacional de las Letras (2003), Hijo Predilecto de Andalucía, Medalla de Oro de Córdoba, Medalla de Oro del Círculo de Bellas Artes y así hasta más de una veintena de premios de toda índole. Quizá, que el gran Paco Ibáñez no hiciera canción alguna de sus poemas entre los años 6o y 7o, lo colocó, a ojos de lectores, oidores y docentes ( $\tan$ prestados al uso del audio en el trabajo de los poemas en la aula) en un segundo plano de la posguerra, aunque gozara de una importante trayectoria poética muy reconocida entre los propios poetas del momento y de las generaciones más inmediatas.

La poesía, dice nuestro poeta, nos acompaña en el sufrimiento y en la alegría, en el desconcierto y en el progresivo conocimiento que vamos teniendo de la vida: es, por tanto, la ventana por la cual miramos el mundo y lo hacemos nuestro, proyectando nuestros deseos y temores, nuestro espacio y nuestro tiempo. Es un cauce de continuo conocimiento a partir de la doble experiencia que la sostiene: lo emocional y lo rítmico, pues las dos vibraciones provocadas por la palabra nos dan el perfil exacto de quiénes somos y cómo se define nuestra mirada a partir de entonces. A esto lo llamó «respirar por 
la herida», como síntesis de su manera de entender la escritura poética como testimonio de una profunda escisión del yo y toma de conciencia del dolor propio y ajeno (Arlandis, 20I9: I3-I8).

Fue el mismo Leopoldo de Luis quien en una carta a la crítica argentina Elena Refojos de Co, en I983, señaló los tres ejes fundamentales de su poesía: el amor, la condición humana y la circunstancia social, y lo que les une es la toma de conciencia de ello, ese citado «respirar por la herida» que tanto defendió (I983: I53). Muy tempranamente (en r942) se proponía Leopoldo de Luis, en el poema «Será sencillamente» (Alba del hijo, I946), escribir una poesía «sin palabras vacías ni artificios inútiles», con lo que dejaba bien clara su preferencia estética. Decía Ángela Vallvey que su escritura se gestaba «en la experiencia cotidiana, en la emoción humilde y el quehacer de cada día» (I998: I2) y Concha Zardoya asentía que frente a esto, «ningún hermetismo culterano velará el sentido de sus versos directos, humanos, conmovedores» (I982: 9). Leopoldo de Luis tuvo la gran virtud de incorporar vocablos de esa vida cotidiana en esa gran rueda del lenguaje poético, sin que decayera ni la intensidad emocional del poema ni su rigor estético, pues siempre «el poema viene a ser un artefacto: un arte hecho. Hecho emoción por la palabra artística» como dijera el propio poeta (Apud. Refojos de Co, I983: I52). Así, del núcleo de esas palabras que cada día usamos, el poeta extraía un renovado significado, una trascendencia que se nos pasó inadvertida: modélico resulta, en este caso, el poema titulado «Fútbol modesto» de su libro Elárbol y otros poemas (I954) donde palabras como bostezo, fatiga, cuero cosido, estadios, obrerillos, muchachitos, balón, bota o camiseta anegan el sentido más hondo y existencial de la escena rememorada, con algunos tintes sociales de lo que es proyectar un juego colectivo a una esperanza también común, condensada en la alegría más humilde que se da en cualquier partido, sea de la categoría que sea. Perseveremos en el citado poema porque sobre él podemos articular una enriquecedora actividad de lectura en el aula de segundo ciclo de Primaria (9-II años) o de Secundaria (I2-I6 años).

Fútbol Modesto

Desmontes amarillos bajo el sol del invierno que pone su piedad, su tibieza en las cosas, que arranca falsas luces de los vidrios verdosos, diamantes de un fantástico sueño por el que cruzan heridos perros de esperanza y pena.

Delgados muchachitos, pálidos obrerillos con sus botas gastadas, bajo sus trajes grises, que van a hacer deporte o a aprender que ellos mismos son un balón doliente que a puntapiés manejan los grandes jugadores de la vida. 
Mañanas de domingo. La carne fatigada bosteza lentamente su cansancio remoto. Una humilde ilusión, como el rayo en los vidrios, arranca de las almas llamitas de alegría.

Bota el cuero cosido de esperanza, hinchado con un aire de esperanza, de risa triste, de ilusión oscura.

Colores desteñidos que nunca se asomaron al sol de los estadios, van, vuelven, corren las camisetas, buscan, persiguen una esfera del color de su sueño. Ascienden desde el pozo insondable del tiempo las horas como sombras, los trabajos, la pena, la miseria, la modesta comida en los platos heridos, sobre el hule, el fondo de la sórdida galería, la cama donde se rinde noche a noche el hueso abatido de llanto silencioso y sin lágrimas. Asciende aquí el cansancio, el destino que, sordo, va cumpliendo sus suertes, la niñez mal cuidada, la escuela pobre, el fuego del brasero amparando a la familia. Todo llega al solar del domingo, confuso, ceniciento, remoto, en el cuero que bota, entre los desvaídos colores de la blusa, y se enreda en las piernas que persiguen ese balón con forma de esperanza.

(Luis, 20I9: 279-28I)

\section{La motivación ante la poesía: generar expectativas y líneas de sentido intra y ex- tratextuales.}

Tengamos en cuenta, primero, los posibles parámetros derivados de los intereses y de la motivación, sustentados por los conocimientos previos. Queda clara la atención a la diversidad si somos conscientes de que no todos los/las estudiantes saben, conocen o les gusta el fútbol, pero sí saben, conocen y son partícipes de una sociedad que construye muchos de sus espacios sociales y culturales en torno a este deporte, su práctica y su competición. Es decir, nadie es ajeno a lo que implica un partido de fútbol en lo económico, en lo social, en lo personal y en lo cultural. 
Las actividades de motivación previas deberían estar asentadas sobre la experiencia propia de los estudiantes: qué recuerdos tienen, con quién ven los partidos, de qué equipo son, si lo practican ellos/as o algún familiar, etc. Y, sobre todo, cómo ven el deporte o cómo ve la sociedad actual (la occidental) este deporte. Sería interesante que se reflexionase sobre el espacio que ocupa el fútbol en los medios de comunicación y cómo se valora al futbolista. Del mismo modo, se podría reflexionar sobre cómo valoran ellos/ as mismos a los futbolistas y qué ven en ellos para considerarlos (si lo hacen) referentes sociales. Así, podemos llevar a los/las estudiantes a hacer un juicio de valor, profundo, de cómo asimilamos una problemática escala de valores en la sociedad y atender sobre qué parámetros estamos articulando nuestras preferencias existenciales como seres humanos. Para entender que están (y estamos) dentro de una sociedad altamente competitiva es necesario que tengan conciencia de ello y, sobre todo, que sepan de qué modo son partícipes, o no, de la construcción de ese modelo social. Obviamente, sin la complicidad de la familia esto no podrá llevarse a cabo nunca plenamente, ya que el aprendizaje significativo, aquel que proyecta lo aprendido sobre la sociedad y la sociedad sobre lo aprendido, tiene la voluntad de coordinar aula y familia, aunque no exista la misma correspondencia en todos los ámbitos familiares. Respondería así, el poema, a esos intereses que, en su gran mayoría, podrían tener los alumnos y las alumnas del aula. Evidentemente, cabría potenciar todas las posibles expectativas (aquel horizonte de Jauss y de la estética de la recepción) de lectura, generar interés y expectación, crear dudas, porque su título no hace referencia (¿O sí?) a ese fútbol de grandes nombres, focos y estadios, sino al que habitualmente convive con la mayoría de los chavales: lo modesto, el equipo del pueblo, de barrio, el de las categorías regionales, de los sueños más diarios o cotidianos, etc. $\mathrm{O}$ quizá no, y esté hablándonos de otra cosa... La cuestión es: ¿para qué leemos el poema? Para resolver nuestra duda, para ver qué visión se tenía del fútbol en los años 50 y si ha cambiado, para saber por qué habla del fútbol modesto, para saber qué quiere decirnos alguien que ve un partido de este modo, para entender por qué alguien pensó en hacer un poema de algo así, para demostrarme que podría leer un poema con éxito, para saber que no toda la poesía está llena de palabras estéticas o más preciosistas, para comprender que todo lenguaje puede ser usado en un poema pero hay que ver cómo se puede hacer o qué necesario es fijarse objetivos de antemano que vayan más allá de la filtración del poema sobre los rígidos esquemas de la lógica, etc. Porque no olvidemos que el propio poema (sea el que sea) solo responde a una lógica en sí: la suya propia, y que a veces esta no se basa en el más estricto raciocinio, sino en lo irracional/emocional, ya que, en ocasiones, se nos pasa la idea de que el/la poeta solo quiere generar una emoción en los lectores usando palabras, cuya combinación, tanto en su disposición gramatical como en su ajuste semántico, se escapa a la estricta normativa lingüística.

Así, podemos cuestionarnos si, con ello, habremos suscitado la necesidad o disposición de lectura (tal y como sugiere Isabel Solé), pero, desde luego, no estaríamos mal encaminados. Y es más, compartimos con buena parte de la crítica especializada en la didáctica que cabe diversificar situaciones, de tal modo que permitan que tanto los/las 
docentes como los alumnos hagan sus aportaciones a la lectura, que puedan negociar los objetivos que se pretenden conseguir, pero sin olvidar que esto requiere que el propio profesor/a «enseñe su proceso» al alumnado, es decir, que muestre cómo llegan él o ella mismos a hacerse estas preguntas previas y a marcarse unos objetivos.

Vayamos pues, al segundo nivel: la comprensión durante la lectura. Evidentemente cabe ir confirmando, durante la lectura, nuestras predicciones. Pronto podemos comprobar que los jóvenes obrerillos, muchachos con pocos medios, no son quienes juegan, sino que son solo parte del juego que otros practican: se representan como marionetas, peones con «humilde ilusión» como dice el poema. Son jóvenes que viven bajo un sueño, de pobre esperanza, de ser protagonistas, aunque no lleguen a ser esos famosos jugadores que llenan estadios. Y existe la reflexión de que esos jóvenes acaban viviendo bajo el látigo de una frustración permanente, porque el deporte no es el ejercicio físico aquí, sino la puerta de un posible éxito tan solo reservado para unos pocos. Podemos hacer que los/las alumnos atiendan a esto mismo haciéndoles que reflexionen sobre el lenguaje que está empleando el poeta y qué términos (qué valor figurativo) se asocian a esos mismos jóvenes, porque comprender no es más, en este punto, que dar una respuesta personal de por qué este poema nos ha generado emociones y cómo lo está consiguiendo, a través de una concreta herramienta: el lenguaje.

Una de las características fundamentales de género poético es su disposición anímica o interiorización, que hace que el poeta tienda a hacer suya la experiencia y la realidad exteriores. Todo esto (aunque excesivamente sintetizado en estas líneas y muy susceptible de verse rebatido atendiendo a tan excesiva abreviación) nos lleva a una palabra que, en contadas ocasiones, se usa a la hora de trabajar un poema en clase: la emoción. Digamos que lo convencional, en estos casos, puede resumirse en el siguiente plan de trabajo: primero, buscar el tema, luego señalar figuras retóricas, como si esto fuera consustancial o exclusivo de la poesía y más tarde, comentar algún aspecto métrico-rítmico. Así, la desconexión parece inevitable, entre otras cosas, porque los propios alumnos/ alumnas van a ver una notable carencia de utilidad en este tipo de textos y en esta manera de aproximarse a ellos. En cambio, los poetas de hoy (por llamarlos de algún modo) sí pueden ser útiles para parafrasearlos en redes sociales, por ejemplo. Y es que parece como si los/las docentes no hubiésemos estado muy atentos a los propios procesos de lectura que se están llevando a cabo y en qué dirección (por no decir utilidad) los/las estudiantes enfocan la lectura de poesía. Por tanto, la poesía es emoción concentrada y debe trabajarse paralelamente así también para alcanzar un objetivo mucho más concreto: la comprensión lectora. Cada texto exige un posicionamiento lector y, en consecuencia, cabe hacer hincapié en el hecho de que la lectura de un poema (pongamos este de «Fútbol moderno») requiere otros mecanismos de aprehensión. Si atendemos a esto, podemos plantearnos las siguientes tres cuestiones fundamentales para leer, trabajar, comprender e interpretar este poema de Leopoldo de Luis, sin escudarnos en la identificación de estrategias expresivas retóricas ni en disposiciones rítmicas: 
1) ¿Qué emoción te transmite el poema y por qué crees que te la transmite?

2) ¿Qué verso (o dos versos) destacarías como el que más te ha impresionado?

3) ¿Qué palabra (o dos palabras) del texto te parece más importante?

No propongamos en todo caso que siempre haya un ejercicio de escritura, porque esto mismo se puede tratar en un espacio de debate, de diálogo abierto e interacción en el aula, así que la creatividad no se restrinja a un efecto de escritura que a veces se torna tedioso para los/las más jóvenes: dejemos que hablen y escuchen, que tampoco es mal ejercicio, pues habilidades lingüísticas son igualmente.

Y luego, en un tercer nivel, (el después de la lectura), volvamos a relacionar esto mismo con la experiencia receptora (sobre lo vivencial, que vimos en la primera fase) que traen consigo los/las estudiantes. El hallazgo puede ser válido si sabemos enfocar la actividad correctamente: establecer conexiones con otras lecturas, tales como Futbolísimos de Roberto Santiago, por ejemplo, que es una saga novelesca; con películas como Quiero ser como Bechkam u otras obras de arte, otros textos (periodísticos, por ejemplo), etc. ya que, como apuntan Ballester e Ibarra (2009: 25-3I), cabe «aprovechar la conexión de los diferentes lenguajes y discursos artísticos como motivación». Es decir, tenemos terreno de sobra para trabajar eso que Guadalupe Jover, con una agilidad terminológica impecable, calificó como constelaciones literarias en su libro Un mundo por leer (2007) y que hoy en día constituye una de las tarimas procedimentales más seguidas dentro de esa heterogénea y ecléctica plataforma teórico-práctica que es la educación literaria. ¿No es esta otra manera de interpretar la obra de un poeta social (no siempre lo fue) como Leopoldo de Luis? ¿No es esta otra manera de acercarse a su obra sin el peso crítico que da a veces el canon historiográfico? ¿Acaso lo importante no es que los/las más jóvenes tengan conciencia de la realidad que viven y que la poesía pueda ser una buena herramienta para desarticular la construcción de una sociedad cuyos valores son realmente discutibles? O vayamos más allá: ¿̨no es útil hacer ver que muchos de esos textos poéticos actuales (o como se les quiera llamar) que les intentan convencer de que eso es el presente y el futuro de la poesía no son más que abortos estéticos en su gran mayoría y de que leer poesía no solo es entender qué te dicen sino valorar o acaso criticar, el cómo te lo dicen? ¿No es tampoco útil conseguir que los/las más jóvenes no vean en lo clásico ese falso muro de desactualización que unos interesados han creado a todo lo que huela a pasado excepto si lo llamamos moda vintage?

\section{La actividad bajo el análisis de sus datos}

Resultaba necesario, para mostrar cómo evoluciona el desarrollo de las competencias lectora y literaria, contrastar esta misma actividad entre estudiantes de Primaria y un grupo de estudiantes universitarios, todavía próximos, en edad, a su paso por Bachillerato o un ciclo de Formación Profesional. Con la intención de no vulnerar la privacidad 
de ningún centro omitiremos la referencia exacta de los centros educativos, pero no su ubicación: el colegio público pertenece a la localidad valenciana de Torrente y el centro universitario está en la ciudad de Valencia. El número total de encuestados tras la actividad fue de I4I en total, siendo 49 estudiantes de Primaria y 92 de Grado universitario.

El perfil de los estudiantes de Educación Primaria sería el siguiente: un arco de edad comprendido entre los 9 y los io años, dependiendo, esta oscilación, de la fecha de nacimiento con respecto al comienzo del curso. Su perfil socioeconómico y cultural es medio y, en algunos casos, bajo, por diferentes motivos: pertenencia a colectivos desfavorecidos, situación familiar inestable, precariedad laboral de los padres, etc. Además, tenemos que un $57 \%$ son niñas y un $43 \%$ son niños. Por su parte, el perfil de los estudiantes universitarios del Grado de Educación Primaria que están cursando su segundo año académico (curso 2OI9-2O2O) es algo más heterogéneo: la franja de edad, salvo en algunas excepciones que la superan, oscila entre los 20 y los 25 años; el nivel socioeconómico y cultural es medio, aunque existe cierta precariedad económica en algunos casos. El porcentaje entre mujeres y hombres es más desigual, ya que estamos ante un $67 \%$ de mujeres frente a un $33 \%$ de hombres.

El cuestionario no era tipo test en su totalidad, sino que incorporaba una respuesta abierta, aunque guiada. La primera pregunta, previa al trabajo de la actividad con las tres preguntas sobre su comprensión e interpretación, era:

$¿$ Crees que has comprendido el poema? Puedes responder:

a) sí, plenamente.

b) sí, aunque no estoy seguro/a de haber comprendido todo su contenido.

c) No he comprendido muy bien el poema.

d) No puedo responder a esa pregunta.

Explica brevemente el porqué de tu respuesta

El grupo de Primaria presentó los siguientes datos: el $29 \%$ afirmaba haber entendido el poema, opción $a$ ), aunque había algunas cosas que les generaban dudas, tal y como argumentaban algunos o algunas en su explicación, con lo que podrían vincularse también a la opción $b$ ), aunque no la señalaran. El 3I \% señalaba que no estaban muy seguros de haber entendido el poema, pero que creían que sí y el $40 \%$ afirmaban que no lo habían comprendido bien a pesar de que había cosas que sí habían comprendido. Tras la realización de la actividad, estos datos se transformaron de la siguiente manera: el $7_{2} \%$ afirmaba que sí, plenamente (a); el I3 \% decía haber comprendido buena parte del texto aunque le quedaban dudas (b) y el i5 \% seguía manteniendo que no había comprendido el poema, alegando cuestiones de léxico o de incomprensión de lo expresado.

Entre los estudiantes del Grado los números eran diferentes antes de realizar la actividad: el $4_{2} \%$ afirmaba haber entendido el poema, opción $a$ ); el $5^{\mathrm{I}} \%$ señalaba que sí 
lo habían entendido aunque tenían algunas dudas al respecto, como si el poema guardase un secreto que a ellos o ellas se les escapase, tal y como algunos o algunas afirmaban. Finalmente, el 7 \% señalaba que no había comprendido el poema. Tras realizar la actividad, y siendo preguntados de nuevo, el 87\% indicaba que había comprendido el poema en su sentido global, el io \% seguía eligiendo la opción b) y el 3 \% continuó manteniendo que no lo había comprendido a pesar del trabajo realizando, siendo la falta de interés por la poesía o la incapacidad para reflexionar sobre ella el objetivo señalado más recurrente.

Los resultados arrojaban una evolución importante en la competencia lectora de las/los estudiantes de los diferentes ciclos y, por tanto, a pesar de que no se dio la plenitud de comprensión del poema, sí resultaron satisfactorios los avances. Visto lo visto, seguramente aquellos estudiantes que en Primaria ya se muestran un tanto reacios a la lectura de poesía seguirán con esta misma actitud dentro de su evolución como personas, pero entendemos que un trabajo temprano que atienda otro modo de trabajar la poesía en un aula puede ayudar a incrementar el número de buenos lectores de poesía y a reducir los reacios.

Llevados entonces a la realización de la actividad, y tras su segunda pregunta que atendía a la indicación del verso más impactante o relevante a su entender, tenemos que el 29 \% del grupo de Primaria que había entendido el poema presentaba los siguientes resultados: un $79 \%$ seleccionaron los versos I3-I4 «Una humilde ilusión, como el rayo en los vidrios, / arranca de las almas llamitas de alegría», donde el uso del diminutivo, la imagen tan luminosa y esa escena tan cándida podrían haber guiado su atención; el 7 \% eligió el verso 37, «ese balón con forma de esperanza»; el $3 \%$ indicaron que su verso preferido era el 33, "Todo llega al solar del domingo, confuso» y otro $3 \%$ señalaron el verso 29 , «Asciende aquí el cansancio», frente al $5 \%$ restante que ya eligió otras opciones muy heterogéneas. Por tanto, si valoramos estos datos, observamos que existe una evolución en la lectura, que la hace ir ganando confianza en la comprensión e interpretación del poema, ya que consideraron que los primeros versos eran puramente contextuales (aplicando en cierta medida un razonamiento narrativo de fondo). Del mismo modo, han primado los aspectos positivos, en la valoración, sobre los negativos, pues «almas llamitas de alegría» o la «esperanza» final se imponen: incluso en los casos donde hay cierta negatividad (confusión o cansancio) pero en los que también aparecen términos arquetípicamente positivos, tales como ascensión o domingo (asociado a festivo o a descanso). Entendemos que el haber tratado previamente cómo ven el mundo del fútbol, cómo valora la sociedad a los/las deportistas, a la idea del esfuerzo de gente que no tiene apoyo pero que lucha por conseguir sus sueños, etc. ha influido positivamente en el trabajo sobre el poema, pues podemos entender que aquellos aspectos más negativos vienen dados por una reflexión, en esta clave, de lo tratado previamente (expectativas frente al texto antes de la lectura), mientras que los positivos, muy relacionados a alegría y esperanza, de igual modo han podido surgir a raíz de una motivación previa en esta dirección.

Del 3г \% que aseguraba que había entendido el poema pero tenía serias dudas de haberlo comprendido en su totalidad, los datos fueron los siguientes: un $56 \%$ eligieron 
los versos I3-I4 igualmente; un I4 \% señalaron, curiosamente, los versos I8-I9, «colores desteñidos que nunca se asomaron / al sol de los estadios»; un $7 \%$ seleccionaron el verso 37, que es el verso final, como vimos; un Io \% indicaron los versos 6-7, «Delgados muchachitos, / pálidos obrerillos con sus botas gastadas», que evidencia una ruptura clara con respecto al resto de lectores, ya que están focalizando su atención en unos protagonistas, muy pasivos en la acción, pero muy activos en la emoción, así que, al proyectarse el poema hacia una mayor profundización, pierden- entendemos- la conexión, con lo que los motivos previos trabajados se estaban imponiendo en esta primeras reacciones ante el texto, de ahí que surgieran dudas sobre su comprensión, pues en un principio sí parece que se van respondiendo expectativas iniciales, pero estas dejan de ir surgiendo y resolviéndose conforme va avanzando la lectura. Finalmente, el i3 \% restante señalaron opciones muy variadas y poco coincidentes.

Siguiendo con los de Primaria, el $40 \%$ que aseguraba no haber entendido el poema indicó, en un $67 \%$ el último verso como el más expresivo, no distanciándose, en este sentido, de aquellos o aquellas que afirmaban haber comprendido plenamente el texto. En un $22 \%$ de los casos se indicaron los versos 6-7, que coincidía con los del segundo grupo en buena medida; y en un ıo\% de las respuestas nos encontramos el casillero en blanco.

Entre los/las estudiantes del Grado de Primaria, en plena formación como docentes, los datos también resultaban reveladores: recordemos que el $42 \%$ había asegurado la plena comprensión del poema, que incluso se calificaba como «fácil»o «sin dificultad» en muchos de los comentarios. Dentro de ese porcentaje, un 8i \% de los casos seleccionaron el verso final como el más significativo o el que mejor condensaba el sentido del poema, poniéndolo en relación con la esperanza que suele llevar consigo el tiempo y la infancia. Un I7 \% indicó que los versos más expresivos eran los 22-23, con aquel «Ascienden desde el pozo insondable del tiempo» y un 2 \% eligió otras opciones muy variadas. Llama la atención cómo, de manera progresiva, la concentración emocional les va encauzando hasta el final, donde frente a la tristeza de fondo, sigue triunfando una esperanza. Las reflexiones previas a la lectura en torno a las ilusiones de los niños y las niñas cuando juegan al fútbol, las expectativas de los familiares, los deseos de fama, etc. fueron decisivos, posiblemente, en su percepción del poema. Ahora bien, por edad o por inquietudes de todo tipo, cabe resaltar que uno de los versos más nostálgicos con visión del tiempo (mirada poco común en un niño o niña de 9 a Io años de edad, como es lógico) sea el elegido para darle valor representativo al motivo emocional que concentra el poema. Esto se confirma en este grupo cuando, al revisar la selección léxica (tercera pregunta de la actividad) en un $22 \%$ del total del grupo se destaca la palabra «miseria»; en un I 7 la palabra «cansancio» o en I3\% el término «tiempo», frente al $9 \%$ de la palabra «esperanza» y el $3 \%$, por ejemplo, de «sueño» entre otros datos. Curiosamente, tanto «sueño» como «esperanza» son de los pocos términos que aparecen tanto en los versos iniciales como en los finales, a diferencia del resto, salvo «cansancio», que también aparece en dos ocasiones, pero no de manera tan localizada entre el comienzo y el final del poema. Frente a esto, destaca la relevancia 
que tiene la palabra «esperanza» pues vertebra, desde su reiteración, todo el poema en sí, ya que aparece en los versos 5, I5-I6 y 37, marcando claramente las tres partes del texto.

En el grupo de Primaria, con respecto a esa señalización o subrayado de los términos claves (pregunta 3 de la actividad), las palabras seleccionadas fueron bastante más previsibles en su ingenuidad: el $5^{2} \%$ señalaron «bota» porque les recordaba a las suyas propias, o porque les parecía que representaba al fútbol, al dinero que uno gasta para jugar, al poder o potencial del/la futbolista (asociación casi sinecdótica), entendiendo que, además, aparece repetida en el poema y esto puede también influir en su selección. El 9 \% de los/las estudiantes marcó la palabra «esperanza» y un 2 \% «balón», seguramente por su doble posición en los dos casos mencionados (inicial y final de igual manera). Si acaso, es digno de reseñar que el $5 \%$ destacó la palabra «pena» y que, en algún momento, esta debió de ser la emoción transferida (quizá también como reflejo de los razonamientos previos a la lectura, donde se daba cabida a la tristeza de tantos niños y niñas que no cumplen su sueño de ser futbolistas) y mostrando cierta empatía con aquellos semejantes de edad de «trajes grises». El dato curioso es que de los alumnos o alumnas que señalaron esta palabra, solo el $2 \%$ pertenecía al grupo que decía haber entendido el poema (previo a la actividad) y el $3 \%$ restante estaba dentro del $40 \%$ que no lo había entendido ¿de qué modo se estaba asociando la tristeza a la propia poesía, dejando ya atrás aquella inicial etapa lúdica y jovial o aquellos tiernos sonsonetes de las nanas?

Cabe preguntarse por la emoción general que ha transmitido el poema: para el colectivo universitario encuestado, el 7т \% opinaba que el texto les había producido tristeza; el ı8\% nostalgia, el so \% esperanza y el i \% otras emociones. Esto, en cierto sentido, confirmaba la selección de los versos claves. Por su parte, en el grupo de los estudiantes de Primaria se señalaba a la esperanza como la gran emoción suscitada, en un 77 \%, y la pena o tristeza en un I9 \%, dejando un $3 \%$ en blanco o sin respuesta y un r \% con otras emociones tan variopintas como la de «enfado». Lo importante, pues, no era qué emoción en sí, sino el hecho de haberla sentido, reflexionado y valorado en sus motivaciones.

En este apartado de la pregunta número 2 de la actividad, así como en la número 3 , no era necesario cotejar evolución o cambio alguno, pues no se pretende formar una concreta visión del poema, sino estimular mecanismos para adentrarse en la comprensión y asimilación de la emoción transmitida, para que se dé pie a una interpretación totalmente personal, bien formada y con suficientes argumentos, emanados de una reconstrucción de sentido interior en cada estudiante.

Otra de las preguntas que se hacía en test evaluativo era la siguiente:

¿Recomendarías este poema para los niños y las niñas para trabajar en el aula de Primaria? Elige una de estas opciones:

a) Sí, sin problema: es muy importante su contenido

b) Solo para más mayores que yo

c) No lo recomendaría: es aburrido 
d) No lo recomendaría: es difícil

Explica brevemente tu elección:

En el caso de los/las estudiantes universitarios solo se ofrecía una variante: la opción $b$ ) se cambiaba por «Solo para estudiantes de Secundaria»

Con todo esto, el $92 \%$ de los estudiantes del Grado universitario afirmaron sentirse motivados a la lectura del poema tras haber trabajado la estimulación de los conocimientos previos (creación de expectativas, activación de saberes y correspondencias extratextuales) y de ciertas inferencias iniciales más o menos confirmadas con la posterior lectura. Ese porcentaje se redujo levemente entre los/las estudiantes de Primaria, ya que en un $89 \%$ dijeron sentir esa misma motivación ante la lectura del poema. Del mismo modo, el 82 \% de los estudiantes del Grado de Educación Primaria recomendaría el texto de Leopoldo de Luis para tratarse y trabajarse en un aula de Primaria, sin problema alguno y un i8 \% sí que lo recomendaría para el ciclo de Secundaria. Por su parte, el grupo de niños y niñas del colegio solo recomendaba el poema en un $68 \%$ y lo calificaba de «bonito» para que lo leyesen otros/as estudiantes del centro; además, un $30 \%$ aseguraban que no lo recomendarían por la dificultad de su léxico, aunque, en algunos casos, les gustaría comprenderlo más porque les parece interesante. Solo un $2 \%$ indicó que era aburrido, no alegando causa o motivo alguno, salvo en un caso que resaltaba que «no me gusta leer».

La penúltima de las preguntas a responder fue la siguiente:

¿Desearías seguir leyendo más poemas?

a) Sí, pero no de este autor

b) Sí, me interesa este mismo autor

c) Sí, pero de otros temas que me interesen más

d) Sí, me interesan los poemas sobre fútbol

e) No, no me gusta la poesía

f) No, no sirve para nada

g) No, me sigue pareciendo muy difícil

h) No lo sé

Explica brevemente el porqué de tu elección:

Finalmente, entre los/las estudiantes del Grado solo el in \% reconocen que les gustaría seguir leyendo más poemas de este autor, admitiendo el desconocimiento de su obra. Para los de Primaria reina la indiferencia, ya que el $27 \%$ afirma que no lo sabe, 
mientras que otro 3 г \% incide en la idea de que sea otro el autor a leer, mientras que nadie muestra interés por el mismo autor. El 29 \% señala que le interesan los poemas sobre fútbol y su explicación se respalda por su conocimiento de la materia y porque le parece «chulo» hacer poemas sobre este deporte. El I3 \% restante se divide entre las otras opciones, salvo también la opción $c$ ), que no recogió voto alguno. Entre los estudiantes del Grado de Primaria hay más disparidad: el $23 \%$ admite que le gustaría seguir leyendo más, pero no de este autor; el i2 \% señala que no le importaría seguir leyendo a Leopoldo de Luis; el r9 \% indica que le interesan otros temas, más allá del fútbol; el 2 \% se quedó con el hecho de seguir leyendo más poemas sobre fútbol, alegando cierta curiosidad y sorpresa ante dicha temática, poco usual (indicaban) entre sus tipificadas lecturas poéticas. El I9 \% seguía manteniéndose en que no iba a continuar su lectura, ya que no le gusta la poesía; un $9 \%$ afirma que la poesía de poco le sirve; a un $8 \%$ les sigue pareciendo difícil y por eso difícilmente leerían poemas por voluntad propia y un $7 \%$ afirma no saber qué hacer. Si vemos, en un $57 \%$ los estudiantes se muestran dispuestos a seguir leyendo frente a ese $36 \%$ que lo niega rotundamente y ese $7 \%$ dubitativo, que podríamos añadirlo al segundo de los bloques que apuestan por la no-lectura. Pensemos que estos son los/las docentes del futuro: aquellos que deben llevar los textos literarios, entre otras cosas, a las aulas de Primaria.

La última de las preguntas era lógica y esperable:

¿Crees que tienes hábito lector? Es decir, ¿lees en tu casa sin que te obliguen a hacerlo?

a) Sí, leo más de 10 libros al año porque quiero

b) Sí, leo 5-10 libros al año porque quiero.

c) Sí, pero leo menos de 5 libros al año porque quiero

d) No lo sé porque solo leo lo que me obligan en el colegio

e) No, no me gusta leer

f) No, no tengo tiempo para leer

g) Me gustaría, pero no puedo comprarme libros o ir a la biblioteca

Si lees por voluntad propia, ¿qué género sueles leer?
a) Narrativa
b) Poesía
c) Teatro
d) Ensayo
e) Otros 
Los libros que lees ¿son los libros de moda o los eliges por voluntad propia?

a) Sí, son los libros de moda

b) No, los elijo por voluntad propia

En este punto los resultados son preocupantes: entre los estudiantes de Primaria, el $66 \%$ dice que solo lee lo que le obligan en el colegio; el $4 \%$ dice leer entre 5 -Io libros al año; el $8 \%$ afirma que les gustaría pero que no pueden comprarse los libros o ir a la biblioteca; el $9 \%$ indica que lee menos de 5 libros al año; un $2 \%$ dice no tener tiempo para leer; un in \% que no les gusta leer. Los datos son demoledores, porque en verdad, solo el $4 \%$ dice tener hábito lector y a un $8 \%$ les gustaría, pero encuentran impedimentos que rápidamente les disuaden de tal deseo. De entre los pocos que leen, el $94 \%$ reconoce que es narrativa y el $6 \%$ poesía (que seguramente estarán vinculando a concretas redes sociales y perfiles). No hay espacio aquí para el teatro. Y para culminar esto, el $92 \%$ asegura que lee, cuando así lo hace, los libros de moda, frente al $8 \%$ que afirma seleccionar los títulos por voluntad propia.

Entre el colectivo de estudiantes universitarios los datos no son mucho mejores: solo el $3 \%$ reconoce tener hábito lector, leyendo más de ıo libros al año; el ı6 \% dice leer entre 5 -IO y el $24 \%$ reconoce leer menos de cinco libros al año por voluntad propia. Frente a esto, un total del $57 \%$ reconoce no leer nada por placer y se parapeta en diferentes argumentos: un $27 \%$ afirma, sin rubor, que no le gusta leer, incluso a pesar de la opción académica que han elegido para su trayectoria profesional en el futuro; un II \% se escuda en la obligatoriedad del centro para defender su falta de interés en la lectura y en la imposibilidad de evaluar, para sí, un hábito lector que, evidentemente, no tienen; finalmente, un $4 \%$ dice no tener dinero ni medios (a pesar de las instalaciones que la propia universidad les brinda) para leer y un $8 \%$ apunta a la falta de tiempo para hacerlo. De los géneros que deciden leer, cuando lo hacen, en un $87 \%$ es narrativa, en un ı2 \% poesía (intuimos- por consultas posteriores- que los autores son Marwan, Defreds, Elvira Sastre, etc.) y un i \% teatro. Con todo, en un 9I \% se nos apunta que los libros los seleccionan por su novedad y su impacto social (estar de moda), mientras que solo un $9 \%$ de los casos apuntan al gusto o interés personales para justificar una lectura frente a otra.

La evolución de la sensibilidad lectora se confirma, plenamente, entre estos dos vectores que, mediante una encuesta, hemos confrontado previamente y tras la lectura y realización de una actividad sobre un poema de Leopoldo de Luis: la poesía está trabajada en las aulas de un modo que, visto lo visto (y sin quitar responsabilidad a todas las partes), solo genera rechazo, más allá de la indiferencia que la actual sociedad pueda estar alimentando y fomentando en aquellas obras y autores/as que no se ajustan a los gustos eventuales de un mercadeo cada vez más evidente en sus estrategias comerciales. Se insiste, en muchos casos, o a tomar el texto como pretexto, tal y como denunciaron Andricaín y Orlando (20I6: 70) o Perriconi y Wischñevsky (ı984: I4) entre muchos otros, o a filtrarlo bajo una lógica- casuística- de lectura, de base narrativa, que choca fundamentalmente 
con los parámetros de la poesía y acaba desmotivando y descentrando a los/las estudiantes, al menos en su consideración previa sobre qué es la poesía y qué rasgos fundamentales la definen, sea o no sea infantil. Y eso lo ha sabido ver, con nitidez, en sus particulares propuestas didácticas, Anna Ballester (2OI7) o Maryta Berenguer (2007), por ejemplo, aunque se necesitarían también algunos matices a sus planteamientos, sobre todo en este segundo caso.

Pensemos que la poesía no quiere acumular lectores, sino lecturas ni pretende que se lean libros de poemas como se consumen películas que nos muestran historias, más o menos elaboradas en su coherencia argumental, o novelas que nos narran aventuras de todo tipo: solo un poema es, en sí, una aventura inabarcable, pero nunca se cierra del todo, rica en matices. En todo caso, hay que garantizar en la escuela que se pongan las herramientas adecuadas ante los/las estudiantes para que esos mismos matices que tanto fundamentan a cada buen poema, se les pueda dotar de sentido y significado, para garantizar, entre otras cosas, también el desarrollo de un criterio estético que les permita dirimir entre un buen o un mal poema, entre un texto que poco aporta a otro que sí lo hace, etc. bien también porque hay (y existen) necesidades emocionales que precisan vehicularse expresivamente y la poesía ayuda a ello; o bien porque sentimos curiosidad o porque buscamos algún tipo de respuesta vital que no somos capaces de ver, aunque la tengamos delante de nosotros, porque no estamos mirando correctamente. Objetivos no nos faltan: ni funciones tampoco.

\section{Reflexión final en torno a las vías de intervención didáctica en el aula: leer es com- prender e interpretar.}

Entre las muchas (o no tantas) posibilidades de innovar en este terreno nos encontramos con las opciones que nos dan la TIC, ya que la «Red puede ser una valiosa herramienta para la recuperación y transmisión de las composiciones» tanto del Cancionero Popular Infantil como de los textos poéticos en general (Cerrillo, 2OI3: II) que pueden trabajarse en Primaria; pero también- y no deberíamos menoscabar este aspecto- por un lado, a la hora de seleccionar los textos poéticos a trabajar en el aula y, por el otro, la manera de buscar significados de los mismos, de manera individual o grupal, como propone acertadamente Martínez Ezquerro (20I6: I-20), sin olvidar que, en verdad, cabe, desde ya, «articular nuevas maneras de entender la educación que tengan una proyección mayor en nuestro entorno» (Campos Fernández-Fígares, 2020: 237). Por tanto, la primera gran tarea de innovación será la selección de textos que puedan estrechar la relación alumn@s/poema, y que la poesía de Leopoldo de Luis, de manera sistemática y generalizada, garantiza, como lo hacen de igual modo tantos otros textos de poesía de autor o de poesía ganada, como en este caso. Se aconseja que no se dedique excesivo tiempo a una visión historiográfica ni del autor ni del poema, al menos como paso previo, porque este será siempre un conocimiento tangencial en su formación como lector. Ahora bien, esta 
información puede servir para alimentar dichas conexiones con otros textos, pero de eso ya cada profesor o profesora sabrá hacer su sayo, en la tercera fase de la lectura.

Afirmó David Cooper (I990) que la comprensión no es un conjunto de habilidades, sino un proceso a través de cual el lector elabora el significado apelando a las claves discernibles en el texto y relacionándolos con sus conocimientos previos. Así, comprender un texto es un proceso interactivo entre esos conocimientos previos y el texto. De algún modo, el planteamiento de trabajo aquí expuesto pretende alimentar el interés o saltar esa barrera invisible que a veces resulta ser la lectura funcional en el aula. Por tanto, no toda lectura debe convertirse en juego, como propugna Gómez Yebra (2OI6), sino que también debemos fomentar una lectura algo más crítica con la realidad, más acorde con la problemática social, porque no se trata de darle la espalda a lo que la humanidad vive cada día y esperar que la experiencia de dicha vida vaya modelando la reflexión sobre la propia realidad en la mente de estos estudiantes. Sería conveniente, a nuestro parecer, dejar de articular la educación literaria, al menos en su praxis, a espaldas del presente y de sus expresiones, porque ese terreno lo está ganando una poética poco trabajada, pero más sensible a ciertas aficiones, intereses o costumbres de los/las más jóvenes y les convence de que no hay otra manera de actuar o de expresarse que no sea así: con un lenguaje en el que la ordinariez toma el control porque es así como espacios televisivos (los realityshows, por ejemplo) están convenciéndoles de que así sea. Sirva como ejemplo el poder irradiador que están teniendo los youtubers y su discurso en torno al pago de impuestos para garantizar un estado del bienestar que, para ellos y ellas, resulta lesivo y para miles de personas, en cambio, se convierte en fundamental y única posibilidad de subsistir con alguna dignidad humana.

Debemos crear lectores críticos, capaces de diseccionar el contexto comunicativo y sus claves, de intervenir sobre la imposición de un canon (Sánchez García, 20I9: I33) que, esta vez sí, le persigue por todos los canales de comunicación que puede, porque antepone el calificativo de «consumidores» sobre el de «lectores». En definitiva, la poesía de Leopoldo de Luis nos puede ser útil para conseguir tan difíciles objetivos, pero tampoco es la única, ya que son miles los casos que podemos usar de este modo. Nos quedamos, no obstante, con su singularidad como poeta y partimos de la convicción más férrea de que es hoy, en este siglo XXI, cuando su lectura se nos hace más necesaria, pues conecta perfectamente con este ambiente enrarecido que la humanidad está viviendo en el umbral de un cambio político-económico de orden mundial desarmónico y desestructurado y sus versos, la conexión de su música, su lenguaje y los temas tratados en sus poemas, nos permiten emocionarnos, tomar conciencia, ordenar emociones, despertar nuestros valores aletargados por la pereza narcisista y cómoda de una sociedad de consumo. Baste con ver otros libros de Leopoldo de Luis, tales como Teatro real (escrito en 1957) para comprender qué vida reflejamos en las redes sociales y por qué lo hacemos; o La luz a nuestro lado (I964) para solidarizarnos con las importantes migraciones de África; o Del temor y la miseria (1985) para pensar ya no solo en la desgracia de nuestra guerra civil, sino también en la que está sacudiendo Siria o Palestina; o el simulacro de esta vida tan falseada por 
unos ideales irreales que nos privan de nuestra propia identidad para crearnos seres totalmente automatizados, como puede verse en el libro Con los cinco sentidos (I970), y así un largo etcétera, porque, como muy acertadamente afirmaron Andricaín y Orlando, «El punto de convergencia en estos ejemplos y la calidad ¿tiene sentido, entonces, hablar de gusto o disgusto por la poesía, o es más exacto hablar de afinidad o rechazo hacia el estilo, la sensibilidad y los temas de determinados poemas y poetas?» (20I6: 27). No se trata de reivindicar la obra de Leopoldo de Luis (que tampoco estaría nada mal), sino de señalar su posible uso en Primaria.

Debemos de ser conscientes de que la sensibilidad (pues se trata de motivarla con esta actividad) no puede evaluarse como tal (Sanjuán, 2OII: 85-87): nada que podamos llevar a cabo en este paso lector (imprescindible paso, no obstante, para el desarrollo de la competencia lectora) podemos cuantificarlo más allá de la participación, de la voluntad y el interés. Así, desde esta perspectiva estamos tratando de fomentar no solo el hábito lector y el placer por la lectura sino también la cooperación entre compañeros y compañeras como uno de los objetivos a alcanzar, ya que la puesta en común (tanto a la clase como a pequeños grupos de trabajo) de diferentes interpretaciones previas nos ayudará a reorganizar las hipótesis de lectura que cada uno se ha marcado, ponernos frente al prójimo y frente a nosotros mismos y valorar cómo nos estamos comportando en sociedad. Si la educación debe guiarnos hacia nuestra sociabilización jacaso la literatura no es un camino ancho y ameno para conseguirlo?

Sin duda, ante este tiempo de incertezas (y la pandemia provocada por la COVID-I9 así lo testifica) en el que la vida humana vuelve a sangrar por el costado más pobre, sus poemas, en cambio, nos invitan a respirar por la herida: No estaría mal que los/ las jóvenes comenzaran pronto a entender que no hay futuro posible sin solidaridad y sin concienciación de que hay muchas formas de ayudar, pero también muchas formas de producir dolor a los demás y que la poesía, por encima de todo, nos ayuda (como dijo el gran poeta valenciano Francisco Brines) a ser tolerantes con los demás y esto implica respeto y cooperación. Creemos que muchos de los problemas sociales actuales vienen provocados por la ausencia de ese mismo respeto y de la tolerancia, como tanto denunció el bueno de Leopoldo de Luis: difícilmente puede superarse este argumento para sentirse motivado y atraído ante la poesía y su lectura. 


\section{Referencias bibliográficas}

-Andricaín, Sergio y Orlando, Antonio (20I6). Escuela y poesía ¿y qué hago con el poema? Cuenca: Publicaciones de la Universidad de Castilla- La Mancha.

- Arlandis, Sergio (20I8). Poesía e internet: los nuevos paradigmas del lector, del autor y del texto, Sánchez, Remedios (coord.). Nuevas poéticas y redes sociales. Joven poesía española en la era digital. Madrid: Siglo XXI, pp. 8I-IOO.

- (2019). Edición crítica y notas de Libre voz. Antología poética (1941-2005) de Leopoldo de Luis. Madrid: Cátedra, pp. I3-210.

- Ballester, Anna (20I7). Poemanía. Guía práctica para hacer lectores de poesía. Alzira: Algar Editorial.

- Ballester, Josep e Ibarra, Noelia (2009). La enseñanza de la literatura y el pluralismo pedagógico. Ocnos: revista de estudios sobre la lectura, $\mathrm{n}^{0}$ 5, pp. 25-36.

- Berenguer, Maryta (2007). Poesías para jugar. Un camino hacia la lectura. Madrid: Los libros de la Catarata.

- Campos Fernández-Fígares, Mar (2020). Corrientes ecológicas y educación literaria en tiempos de incertidumbre, en Ballester, Josep e Ibarra, Noelia (coords.). Entre la Lectura, la Escritura y la Educación. Paradigmas de investigación en Didáctica de la Literatura y la Lengua. Madrid: Narcea. 237-254.

- Cassany, Daniel (2006). Taller de textos. Leer, escribir y comentar en el aula. Barcelona: Paidós.

- Cassany, Daniel; Luna, Marta y Sanz, Glòria (ı993, 2000). Ensenyar lengua. Barcelona: Graó.

- Cerrillo, Pedro (I996). El lenguaje no esperable: el género de las "suertes”, en García Padrino, Jaime (ed.). Y voy por un caminito... Homenaje a Carmen Bravo-Villasante. Madrid: Publicaciones de la Asociación Española de Amigos del Libro Infantil y Juvenil, pp. II5-I26.

- Cerrillo, Pedro y Luján, Ángel L. (20IO). Poesía y educación poética. Cuenca: Publicaciones de la Universidad de Castilla- La Mancha.

- Cerrillo, Pedro (2013). Prólogo, en Sánchez, César. Poesía, infancia y educación: el cancionero popular infantil en la escuela 2.o. Cuenca: Publicaciones de la Universidad de CastillaLa Mancha, pp. 9-I2.

- Cervera, Juan (1997). La creación literaria para niños. Bilbao: Mensajero. 
- Coll, César et alii (I994). El constructivismo en el aula. Barcelona: Graó.

- Colomer, Teresa (1999). Introducción a la literatura infantil y juvenil. Madrid: Síntesis.

• Cooper, J. David (1990). Cómo mejorar la comprensión lectora. Madrid: Visor.

- Díez de Ulzurrun, Ascen (coord.). (1998). L'aprenentatge de la lectoescriptura des d'una perspectiva constructivista. Vol 1. Activitats per fer a l'aula: textos funcionals i contes. Barcelona: Graó.

- Gómez Yebra, Antonio (20I6). Animación a la lectura y literatura juvenil. Sevilla: Renacimiento.

- Held, Jacqueline (1987). Los niños y la literatura fantástica. Función y poder de lo imaginario. Barcelona: Paidós.

- Jover, Guadalupe (2007). Un mundo por leer. Educación, adolescentes y literatura. Barcelona: Octaedro.

- Kozak, Débora, Kriscautzky, Marina y Díaz, María B. (I994). Caminos cruzados (constructivismo y contenidos escolares). Buenos Aires: Aique Grupo Editor.

- López Tamés, Román (1990). Introducción a la Literatura Infantil. Santander: Universidad de Santander-ICE.

- Luis, Leopoldo de (2019). Libre voz. Antología poética (1941-2005) de Leopoldo de Luis. Edición crítica a cargo de Sergio Arlandis. Madrid: Cátedra.

- Martínez Ezquerro, Aurora (20I6). El método de cooperación interpretativa como estrategia lectora. Alabe, $\mathrm{n}^{\circ} \mathrm{I} 4$, pp. I-20.

En línea: DOI: http://dx.doi.org/IO.I5645/Alabe2OI6.I4.I

- Melanio, Óscar y Dávila, Giovanna (20I8). El modelo de buen lector y la formación del comportamiento lector. UCV-Scientia. Vol IO, n I, pp. 82-92.

- Moreno, Víctor (2OII). Cómo hacer lectores competentes. Guía práctica: reflexiones y propuestas. Pamplona: Pamiela.

- Perriconi, Graciela y Wischñevsky, Amalia (I984). La poesía infantil. Estudio preliminary antología. Buenos Aires: Editorial El Ateneo.

- Refojos de Co, Elerna (1983). Leopoldo de Luis o la palabra densa, densa. Un estudio crítico sobre un poeta español contemporáneo. Buenos Aires: Talleres Gráficos de Robert y CIA. 
- Sánchez García, Remedios (20r9). Cuando la Literatura (también) es ideología. Del canon literario al canon escolar, en Campos Fernández-Fígares, Mar y Quiles, Ma del Carmen (coords.). Repensando la Didáctica de la Lengua y la Literatura. Paradigmas y nuevas líneas de investigación. Visor: Madrid, pp. I3I-I44.

- Sanjuán, Marta (2OII). De la experiencia de la lectura a la educación literaria. Análisis de los componentes emocionales de la lectura literaria en la infancia y la adolescencia. Ocnos: revista de estudios sobre la lectura, $\mathrm{n}^{\circ}$ 7, pp. 85-100.

- Sevilla, Santiago (2018). «La aventura interminable: algunas claves sobre la motivación y los procesos de lectura». Revista Cálamo FASPE, no 66, pp. I-6. En línea: https://ebuah. uah.es/dspace/handle/roor7/41882

- Solé, Isabel (2002). Estrategias de lectura. Barcelona: Graó-ICE.

- Vallvey, Ángela (r998). Huésped de un tiempo sombrío. Breve introducción a la poesía de Leopoldo de Luis, en Luis, Leopoldo de. En las ruinas del cielo de los dioses. Antología (I946-I998). Madrid: Hiperión, pp. 9-18.

- Zardoya, Concha (1982). Leopoldo de Luis. Madrid: Ministerio de Cultura. 